\title{
GUERRA FISCAL ENTRE OS ESTADOS, A GLOSA DE CRÉDITO TRIBUTÁRIO E A AFRONTA AO FUNDAMENTO DA LIVRE INICIATIVA TRACEJADO NA CARTA CONSTITUCIONAL DE 1988
}

\author{
FISCAL WAR BETWEEN THE STATES, THE GLOSSARY OF TAX \\ CREDIT AND THE ADOPTION OF THE FOUNDATION OF THE FREE \\ INITIATIVE TRAFFICKED IN THE 1988 CONSTITUTIONAL CHARTER
}

\author{
Daniela Ramos Marinho Gomes ${ }^{1}$ \\ Roberto da Freiria Estevão ${ }^{2}$
}

Data de recebimento: 28/04/2018

Data de Aprovação: 21/07/2018

\section{RESUMO}

Em agosto de 2017 foi publicada a Lei Complementar 160/2017 cujo texto, em síntese, permitiu aos Estados e ao Distrito Federal firmarem convênio para manter os incentivos por mais tempo e perdoar dívidas tributárias de contribuintes autuados. Este trabalho objetiva demonstrar que apesar da edição

\footnotetext{
1 Possui graduação em Direito pela Fundação de Ensino Euripides Soares da Rocha - UNIVEM (2005), pós-graduação lato sensu em Direito Empresarial com ênfase em Tributário pela Universidade Estadual de Londrina - UEL e mestrado em \&quot;Direito Negocial\&quot; pela Universidade Estadual de Londrina - UEL. Atualmente é professora da graduação do Centro Universitário Eurípides de Marília-UNIVEM, nas áreas de Direito Tributário e Direito Econômico e é Vice-Líder do Grupo de Pesquisa DIREITOS DOS GRUPOS VULNERÁVEIS E INCLUSÃO SOCIAL (GIS).

Atua como advogada na área de Direito Tributário e Econômico.

\begin{abstract}
${ }^{2}$ É graduado no Curso de Direito pela Faculdade de Direito da Alta Paulista Tupã Sp (1980), especialista em Processo Penal pela PUC-SP, mestre em direito pelo UNIVEM/FUNDAÇÃO, Doutor em Ciências Sociais pela UNESP-Marília, vice-líder.do grupo de pesquisa "DIFUSO - Direitos Fundamentais Sociais". Atualmente é professor titular do Centro Universitário Eurípides de Marília - UNIVEM/Fundação, de Marília, Membro do Ministério Público do Estado de São Paulo - Procurador de Justiça Aposentado. Tem experiência na área de Direito, com ênfase em Direito Processual Penal, Filosofia do Direito, Introdução ao Estudo do Direito e História do Direito. Tem como principais atuações e temas: processo penal, direitos fundamentais, retórica e direito; procedimento do júri, história do Direito. Ministra palestras e cursos sobre Retórica, Oratória e Direito, temas de Direito Processual Penal, Direito Processual Penal Constitucional, Direito Penal, Direito Penal Constitucional, Direitos Humanos e Fundamentais e História do Direito. Atua (2016) como Vice Líder do Grupo de Pesquisa DiFuSo - Direitos Fundamentais Sociais e Participa (2017) como pesquisador do Grupo de Pesquisa "Direito, cotidiano e construção da sociabilidade"
\end{abstract}


de novas normas, o problema persiste, pois, apesar de quórum mais flexível trazidos pelas disposições normativas, os contribuintes poderão ser glosados, acaso os Estados não se entendam perante o CONFAZ - o que faz prevalecer a afronta ao fundamento da Ordem Econômica Constitucional. Para tanto, este trabalho estruturou-se em três partes. A primeira apresenta o pacto federativo e a competência para criação de tributos no Brasil. A segunda volve-se para os benefícios fiscais que são concedidos pelos Estados que acabam por deflagrar a guerra fiscal com enfoque recentes alterações normativas, oportunidade em que se apresenta o papel do Confaz atribuído pela Carta de 1988. Centra-se, por fim, na investigação da Ordem Econômica Constitucional, donde resultou o fundamento da livre iniciativa.

\section{PALAVRAS-CHAVE}

Guerra fiscal, glosa, Ordem Econômica Constitucional.

\section{ABSTRACT}

In August 2017 Complementary Law 160/2017 was published, whose text, in summary, allowed the States and the Federal District to sign an agreement to maintain the incentives for longer and to forgive tributary debts of assessed taxpayers. This paper aims to demonstrate that despite the issue of new standards, the problem persists, because, despite a more flexible quorum brought by the normative provisions, taxpayers can be glossed over, perhaps the states do not understand the CONFAZ - which makes the affront prevail to the foundation of the Constitutional Economic Order. Therefore, this work was structured in three parts. The first presents the federative pact and the competence to create taxes in Brazil. The second deals with the tax benefits granted by the states that end up triggering the tax war with a focus on recent normative changes, an opportunity in which the role of the Confaz attributed by the Charter of 1988 is presented. Ot focuses, finally, on the investigation of the Constitutional Economic Order, which resulted in the foundation of free Initiative.

\section{KEYWORDS}

Fiscal war, gloss, Constitutional Economic Order. 


\section{INTRODUÇÃO}

Nos últimos anos, ao judiciário se tem levado inúmera batalhas em decorrência do conflito tributário entre os Estados, notoriamente conhecido como Guerra Fiscal do ICMS.

O ICMS - Imposto sobre Circulação de Bens e Mercadorias - é a maior receita dos Estados-membros e Distrito Federal, motivo pelo qual, quando um Estado concede benefícios e incentivos ao ICMS, outros entes federados também o fazem na incessante busca de recursos para seu território.

Tais benefícios revestem-se nas formas de isenção, redução da base de cálculo, redução de alíquotas, crédito presumido, dentre outros, conferidos pelos Estados que acabam por reduzir os tributos, figurando como atrativo às empresas para que se instalem no Estado redutor.

Ocorre que, conforme explícito dispositivo constitucional adiante tratado neste trabalho, os incentivos fiscais somente podem ser concedidos com expressa anuência do CONFAZ (Conselho Nacional de Política Fazendária), a quem compete promover a celebração de convênios para efeito de concessão ou revogação de isenções, incentivos e benefícios fiscais do imposto.

Apesar desta previsão, muitos Estados com o intuito de atraírem capitais e investimentos privados para seu território, concedem à determinadas empresas, incentivos tributários sem validação do CONFAZ, de forma a reduzir o valor da tributação do ICMS nas operações interestaduais. Prevalece a concepção de que os investimentos empresariais, em regra, não se destinariam ao território do Estado cedente em caso de ausência de tais vantagens. Surge então a famigerada guerra fiscal.

Uma saída encontrada pelo Estado para afastar os efeitos decorrentes da guerra fiscal foi editar atos normativos com vistas a punir seus próprios contribuintes, por meio da chamada glosa de crédito. Com esta medida, a empresa que recebe mercadorias oriundas de Estados concessores de benefícios e aproveitam o crédito tributário destacado na nota fiscal acabam sendo submetidas a multas de grande monta.

Para afastar os deletérios efeitos da guerra fiscal, em agosto de 2017 foi publicada a Lei Complementar 160/2017 cujo texto, em síntese, permi- 
tiu aos Estados e Distrito Federal firmarem convênio para manter os incentivos por mais tempo e perdoar dívidas tributárias de contribuintes autuados.

Este convênio foi, enfim, publicado em 18/12/2017 (Convênio 190/2017), estabelecendo as regras para convalidação dos benefícios fiscais existentes, mediante a publicação no Diário Oficial do Estado ou do Distrito Federal da relação com a identificação de todos os atos normativos. Além da condição acima, para validação dos benefícios, há necessidade de expressa anuência de $2 / 3$ das unidades federadas, e de $1 / 3$ de cada uma das unidades federadas de cada uma das 5 regiões do país.

Neste cenário é que emerge o propósito deste trabalho que busca demonstrar que, a despeito das novas disposições normativas, a glosa de créditos aos contribuintes irá persistir, mantendo grave afronta ao fundamento da Ordem Econômica Constitucional, notadamente ao que revela a livre iniciativa, como núcleo estruturante dos negócios que se dão no ambiente brasileiro.

Com o propósito em menção, o trabalho estruturou-se em três partes. A primeira apresenta o pacto federativo e a competência para criação de tributos no Brasil, à medida em que nosso ordenamento jurídico a distribui apenas para as pessoas políticas (União, Estados, Município e Distrito Federal). A segunda volve-se para os benefícios fiscais que são concedidos pelos Estados que acabam por deflagrar a guerra fiscal, oportunidade em que se esmiuçará o papel do Confaz atribuído pela Carta de 1988 e apresentará os delineamentos das recentes alterações. Após delineamento de mencionado aspecto, este trabalho centra-se, por fim, na investigação da Ordem Econômica Constitucional para conhecer a apontar que a punição perpetrada pelos Estados às empresas que utilizam os créditos advindos de lei concessora de benefício fiscal sem validação do CONFAZ, além injusta, contraria os fundamentos ordem econômica esposada na Constituição Federal de 1988, operando na contramão do fortalecimento das empresas que constituem a força motriz da sociedade brasileira.

A pesquisa se deu de forma exploratória com análise bibliográfica a partir de coleta de dados em material científico e informativo atualizado sobre o assunto abordado. 


\section{O PACTO FEEDERATIVO, A DISTRIBUIÇÃO DE COMPETÊNCIA TRIBUTÁRIA NO BRASIL E OS REGIMES DE TRIBUTAÇÃO DO ICMS NAS OPERAÇÕES INTERESTADUAIS}

O Brasil optou por se organizar e dividir politicamente em forma de Federação, criando-se assim, o Estado Federal Brasileiro, sendo dotado de soberania perante os entes federativos que a ele deram origem, isto é União, Estados-Membros, Municípios e Distrito Federal.

Nessa seara, tamanha é a importância para o nosso País que tal estrutura está consagrada no artigo $60, \S 4^{\circ}$, inciso I de nossa Constituição Federal, possuindo o status de Cláusula Pétrea.

Isso quer dizer que os entes que se uniram em forma de Federação, com a finalidade de preservarem suas personalidades políticas, não podem, à sua revelia, ser divididos, desmembrados ou incorporados a outros. (CARRAZZA, 2002, p.125)

Em virtude da adoção do sistema federalista, a União e os Estadosmembros são entes autônomos, ocupando o mesmo plano hierárquico, devendo receber o mesmo tratamento jurídico-formal. A única diferença existente se dá nas competências distintas que receberam da Constituição Federal. (CARRAZZA, 2002, p.123)

Por força do aludido, os Estados-membros possuem a faculdade de se auto-organizarem, o que fazem por meio de suas próprias Constituições, as quais, em obediência ao pacto federativo, devem seguir os mandamentos da Lei Maior, diploma no qual estabelece toda a estrutura a ser observada.

Portanto, tem-se uma autonomia relativa. "A Constituição Federal, como já acenamos, demarca sua faculdade constituinte, mediante a repartição de competências entre a ordem jurídica parcial central (a União) e as ordens jurídicas parciais periféricas (os Estados federados)." (CARRAZZA, 2002, p.133)

Há de se ressaltar ainda que os Estados-membros não são autônomos apenas em relação à União, mas também entre si. Desse modo, não importa o seu tamanho, riqueza ou população, devendo todos receber tratamentos isonômicos, possuindo as mesmas prerrogativas, obrigações e participando, de igual modo, da formação da vontade nacional. (CARRAZZA, 2002) 
Tendo em vista que é por meio de sua Lei Maior que o Estado Federal exerce sua soberania sobre os entes federados, em nosso Estado Brasileiro não poderia ser diferente, visto que "nossa Carta Magna estruturou o País sob a forma de Federação e, para reforçá-la, repartiu as competências legislativa (inclusive as tributárias) entre a União e os Estados-membros." (CARRAZZA, 2002, p.140)

Desta forma, impende consignar que, por força do pacto federativo, cada ente deve instituir e arrecadar, em caráter privativo, o tributo que lhe fora atribuído pela Constituição Federal, sem que os demais interfiram nessa autonomia, uma vez que, em se tratando de matéria tributária, não podem estes invadir a competência alheia.

Nessa ordem de ideias, uma enorme gama do sistema de tributação brasileira está positivada na atual Constituição Federal, ao passo que esta, cumprindo o pacto federativo outrora abordado, delimita exatamente quem será competente para legislar e o que poderá ser realizado no que diz respeito aos tributos em nosso país.

Assim, quando se trata de matéria tributária e em razão de esta estar descrita na mais alta hierarquia jurídica do Brasil, qual seja, a Carta Magna, os competentes para exercitá-la deverão sempre observar e se limitar ao que este diploma os possibilita, atuando sempre à luz do texto constitucional, não ultrapassando assim suas competências. (CARRAZZA, 2002, p.23)

Com efeito, no que tange à competência para criação de tributos no Brasil, nosso ordenamento jurídico a distribui apenas (privativo) para as pessoas políticas (União, Estados, Município e Distrito Federal):

Tem competência tributária, no Brasil, as pessoas políticas, ou seja, a União, os Estados, os Municípios e o Distrito Federal. Isto porque só elas possuem Legislativo Próprio. E, como procuramos demonstrar, é o Poder Legislativo - e apenas ele - que, em nosso ordenamento jurídico, está credenciado a criar tributos. (CARRAZZA, 2002, p.24)

Ainda que a competência para a criação de tributos seja privativa aos entes políticos sobreditos, estes possuem determinadas limitações, haja vista 
que, mesmo que dentro desta faculdade o legislador tenha uma liberdade de criação de tributos, deverá este seguir uma regra matriz para tal.

Neste palmilhar, o ordenamento jurídico delimita os tributos que cada ente político poderá criar, de modo que, cada qual não poderá invadir, anular ou usurpar a competência do outro, pois, assim, estar-se-á descumprindo o sistema federativo adotado por nosso País.

Deste modo, cabe neste trabalho, em breve linhas, demonstrar a competência distribuída pelo Estado Federal (Federação Brasileira) aos seus respectivos entes políticos.

Os Municípios estão aptos a criar os impostos contidos no artigo 156, inciso I a III de nossa Lei Maior, como Impostos sobre a Propriedade Predial e Territorial Urbana (IPTU), os Impostos sobre Serviços (ISS) e os Impostos sobre Transmissão de Bens Imóveis (ITBI).

Por sua vez, o Distrito Federal, dentro de seu território, é competente para criar os mesmos impostos concedidos aos Estados-membros e Municípios, conforme preceituam os artigos 155 "caput" e 147 in fine, ambos da Constituição Federal.

Já a União poderá criar os tributos inseridos no artigo 153 da CF, bem como, em atenção ao artigo 154 do Diploma Supremo, outros tributos não previstos no artigo mencionado, desde que o façam por meio de lei complementar, não sendo estes cumulativos e não possuindo fato gerador ou base de cálculo próprios discriminados pela Constituição Federal. Trata-se da competência residual da União.

Por fim, porém não menos importante, aos Estados-membros compete instituir os impostos descritos no artigo 155, I a III da Carta Magna, ou seja, os Impostos sobre a Propriedade de Veículos Automotores (IPVA), os Impostos sobre a Transmissão Causa Mortis e Doação (ITCMD) e, finalmente, os Impostos que versem sobre a Circulação de Mercadorias e Prestações de Serviços Interestaduais e Intermunicipais e de Comunicação (ICMS).

Nesta tessitura, destaca-se que, após a delimitação da competência, não se sabia ao certo de quem seria a arrecadação quando a operação fosse realizada por contribuintes de Estados diferentes (operações interestaduais), dúvida que fora devidamente sanada com a escolha do regime de tributação do ICMS. 
Isso porque, quando se trata de operações interestaduais, a Constituição Federal dispõe em seu artigo 155, § $2^{\circ}$, inciso VII e VIII o fenômeno chamado de "diferenciação de alíquotas".

O intuito dessa disposição é preservar os Estados onde estiverem localizados os consumidores finais da mercadoria ou serviços suscetíveis à tributação do ICMS. (CARRAZZA, 2002, p. 331)

Deste modo, inexistindo prestações e operações seguintes tributáveis por meio do ICMS, a diferenciação nas alíquotas funciona como um fator de compensação aos Estados.

Logo, a aludida diferenciação contempla não só vantagens aos Estados, como também aos consumidores, vez que esta, ao servir como instrumento de compensação, irá, obviamente, refletir de forma direta no preço final da mercadoria.

Com efeito, tal compensação impede que os consumidores se desestimulem a comprar os produtos à venda no próprio Estado em razão de estes possuírem carga tributária menor em outros Estados e consequentemente menores preços quando colocados em comercialização:

Ademais, não fosse o diferencial de alíquotas haveria um forte desestímulo à compra de mercadorias ou à fruição de serviços, por parte dos consumidores finais, nos próprios Estados em que estão sediados ou domiciliados. Com efeito, seria para estes consumidores finais muito mais vantajoso adquirir tais bens ou usufruir tais serviços em outras unidades federativas, já que a carga econômica representada pelo ICMS seria sensivelmente menor. (CARRAZZA, 2002, p. 332)

Verifica-se que alíquota diferenciada possui o propósito de repartir aos Estados produtores e consumidores - origem e destino - os valores arrecadados a título de ICMS nas operações interestaduais.

Nessa seara, imperioso destacar que nossa Carta Magna veda que os Estados efetuem discriminações tributárias em razão da origem ou destino da mercadoria.

Para a Lei Maior do Estado Federal, bens e serviços devem ser submetidos a um tratamento equânime, de modo que estes possam circular 
sem quaisquer barreiras fiscais, preservando, deste modo, a unidade política econômica nacional. (BALEEIRO, 2010, p. 442)

Outrossim, com o fito de alcançar uma harmonização em relação as tributações do ICMS, a Constituição Federal, nas operações interestaduais, adota alguns princípios para que a mercadoria, bens ou serviços não sejam tributados duas vezes, isto é, no Estado de origem e no Estado de destino.

Segundo os ensinamentos de BALEEIRO (2010, p. 442) “o objetivo não é apenas impedir a elevação do preço da mercadoria pela transferência da dupla carga tributária, mas, sobretudo, permitir, em relação a certo Estado, que os bens advindos de outros possam concorrer em igualdade de condições com aqueles locais".

Tal regime foi adotado porque, dessa forma, ao contrário da tributação ocorrida apenas no Estado de destino, ambos os Estados - origem e destino - são beneficiados com o recolhimento do ICMS.

Por essa razão, esse modelo de tributação também é conhecido como "mercado integrado". De acordo com os doutrinadores, a opção pelo sistema contido no primeiro princípio (Estado de destino) seria um retrocesso à integração do mercado.

Cabe ao Senado Federal o poder e competência para fixar as alíquotas aplicáveis nas operações interestaduais.

Inicialmente, o Senado Federal, visando regular o tema, estabelece como alíquotas máximas interestaduais um percentual inferior ao máximo fixado para as alíquotas internas. Posteriormente, passa a se utilizar de outra ideia, qual seja se o Estado de destino da mercadoria estiver situado nas Regiões Norte, Nordeste ou Centro-Oeste (chamados de importadores-consumidores líqüidos), a alíquota interestadual será reduzida, vindo a reduzir a receita do Estado de origem, situado na região Sul-Sudeste (considerados exportadores líqüidos).

Para tanto, o motivo dessa diferenciação de alíquotas é justamente trazer vantagens ao Estado de destino, uma vez que, assim, a diferença entre as alíquotas - Estado de origem e Estado de destino - será maior.

Tal diferença de tratamento não é considerada ofensiva, visto que "ela pretende uma verdadeira integração, com neutralidade de resultados - ou 
pelo menos sua atenuação - entre Estados consumidores líqüidos e produtores - exportadores líqüidos." (BALEEIRO, 2010, p. 444).

Destarte, como meio de se manter a isonomia entre os Estados, para concessão de incentivos, isenções e outros benefícios tributários relacionados com o ICMS, exige-se prévio convênio, a ser realizado entre os Estados-membros e Distrito Federal junto ao Senado Federal.

\section{OS BENEFÍCIOS FISCAIS DEFLAGRADORES DA GUERRA FISCAL E O PAPEL DO CONFAZ}

Como é cediço, a Guerra Fiscal do ICMS consiste na concessão de incentivos fiscais às empresas privadas - isenção, redução da base de cálculo, redução de alíquotas, crédito presumido, dentre outros - de modo que por meio desses, o valor a ser tributado à título de ICMS será consideravelmente reduzido, gerando, desta forma, mais lucros às empresas que decidam se instalarem no Estado redutor.

Nesse passo, Alves define Guerra fiscal como "todo tipo de disputa/ conflito que decorra da intervenção estatal de entes federativos na decisão locacional de atividades produtivas e na concorrência setorial, sendo que, o instrumento tributário é o principal mecanismo de subsidiamento" (2001, p. 30).

Recorda-se que o ICMS é a maior receita dos Estados-membros e Distrito Federal, motivo pelo qual, quando um Estado concede benefícios e incentivos ao ICMS, outros entes federados também o fazem na incessante busca de recursos para seu território:

Outro fator importante para o início dos conflitos entre os entes públicos é a abismal diferença de desenvolvimento entre eles. Hoje a República Federativa do Brasil possui Estados muito à frente dos demais, no que se refere aos aspectos econômicos e sociais. Visando a equilibrar ou, quando menos, diminuir a diferença que os separam, entes com menor 21 desenvolvimento buscam, com todos os meios de que dispõem, atrair aos seus domínios territoriais empresas teoricamente capazes de alavancar o seu crescimento. Portanto, são essas disparidades econômica, social e política, tão visivelmente 
encontradas no seio da nossa Federação, que movem as pessoas políticas de direito público a instaurar disputas tributárias, objetivando sempre, desenvolvimento e maior arrecadação. (MARQUES, 2010, p. 128).

O Estado "vencedor" da batalha por investimentos privados busca gerar empregos, arrecadação e desenvolvimento econômico.

Segundo Melo (2004, p. 274/275), os incentivos são divididos em 04 (quatro) grupos, a saber: fiscais, financeiros, estímulo para infra-estrutura e outros estímulos.

Em virtude das mais variadas formas, o Supremo Tribunal Federal se posicionou no sentido de que, no âmbito fiscal, estes não são apenas isenções, reduções na base de cálculo, dilação de prazos para pagamento ou créditos presumidos e sim todos incentivos fiscais que impliquem em uma redução da carga tributária. (ARZUA, n. 81, p. 212)

No que tange ao ICMS, os benefícios e incentivos usualmente concedidos são as isenções, reduções da base de cálculo, redução de alíquotas e o crédito presumido, que passaremos a discorrer brevemente.

Nessa seara, importante trazer o conceito de isenção, o qual nada mais é que uma limitação legal - vinculada ao princípio da legalidade - que impede o nascimento do tributo ou que o diminua quando este não possuir apenas isenção parcial. (CARRAZA, 2002, p. 361)

Em outras palavras, a isenção tributária é um benefício concedido ao sujeito passivo, desonerando-o da obrigação de pagar o imposto; ou seja, esta dispensa o contribuinte beneficiado do pagamento integral ou de parte do tributo. Daí o porquê de esta ser uma das hipóteses de exclusão do crédito tributário, conforme se depreende da análise do artigo 174, inciso I do CTN.

Como assinalado no presente trabalho, essas devem ser precedidas de anuência dos convênios celebrados com o CONFAZ, o que, na maioria das vezes, não é observado pelos entes federativos justamente com intuito de vencerem seus concorrentes (demais entes) na disputa (Guerra Fiscal) pelos investimentos de capitais privados em seu território.

Lado outro, a redução da base de cálculo ocorre quando o tributo incide apenas sobre a parte do valor desta operação ou prestação, de modo que 
estas não serão completamente utilizadas como bases para o cálculo do ICMS.

Desta forma, quando houver a incidência da alíquota do aludido imposto sobre parte da base de cálculo de determinada prestação ou operação, o valor tributado a título de ICMS será reduzido.

Logo, com menos imposto a se pagar, o Estado redutor torna-se um atrativo para receber os investimentos privados.

Outro benefício comumente dado pelos Estados para atrair investimentos, é chamado de "bônus" dos entes federativos aos contribuintes do ICMS que se dá por meio do crédito presumido.

Com efeito, o crédito presumido nasce quando da apuração do valor a ser pago de ICMS na saída da operação ou prestação ocorrida (quando a operação acontece). Nesse valor incide um percentual, constituindo de forma fictícia um crédito que será utilizado para reduzir o valor do tributo.

Nessa modalidade de incentivo, verifica-se que os Estados, com intuito de seduzirem as empresas, concedem o crédito presumido aos contribuintes, os quais, quando somados com aqueles obtidos por meio de entradas de mercadorias, irão diminuir a carga tributária do ICMS. (MARQUES, 2010, p. 125)

Importante lembrar que esses incentivos somente podem ser concedidos com o aval do CONFAZ (Conselho Nacional de Política Fazendária), em clara conformidade ao artigo $155, \S^{\circ}$, inciso XII, alínea g da CF e ao artigo $2^{\circ}$, $\S 2^{\circ}$ da LC n. ${ }^{\circ} 24$ de 1975.

Neste ponto, impõe esclarecer que o CONFAZ é um órgão vinculado ao Ministério da Fazenda instituído no dia 07 de janeiro de 1975 pela Lei Complementar n. ${ }^{\circ} 24$.

A este órgão "compete promover a celebração de convênios, para efeito de concessão ou revogação de isenções, incentivos e benefícios fiscais do imposto de que trata o inciso II do art. 155 da Constituição, de acordo com o previsto no $\S 2^{\circ}$, inciso XII, alínea “g”, do mesmo artigo e na Lei Complementar $n^{\circ} 24$, de 7 de janeiro de 1975." (BRASIL)

O conselho se reúne ordinariamente a cada três meses, sendo suas reuniões presididas pelo Ministro da Fazenda ou por algum representante indicado por este. (BRASIL)

Este conselho foi criado justamente "com o objetivo de deliberarem 
sobre elaboração de políticas e harmonização de procedimentos e normas inerentes ao exercício da competência tributária dos estados e do Distrito Federal, bem como colaborar com o Conselho Monetário Nacional (CMN)." (BRASIL)

Fazem parte deste órgão os representantes de cada Estado-membro, do Distrito Federal e um do Governo Federal, o qual é nomeado pelo Chefe do Poder Executivo. (CARRAZZA, 2002, p. 365)

Frise-se que em regra, o nomeado é o Secretário da Fazenda e este é apenas um representante do Governador, não podendo, de forma alguma, legislar a respeito do ICMS. Caso isso acontecesse seria uma ofensa à Constituição Federal e ao Pacto Federativo adotado pelo Brasil como princípio de nossa República, visto que, assim, o Poder Executivo estaria usurpando a competência do Poder Legislativo.

Há de ressaltar que nas reuniões do CONFAZ também se faz presente a Procuradoria Procuradoria-Geral da Fazenda Nacional (PGFN), a Secretaria da Receita Federal (SRF) e a Secretaria do Tesouro Nacional (STN).

Pois bem, em se tratando de Imposto sobre Circulação de Mercadoria e Serviços, os membros do conselho se reúnem e firmam convênios com o intuito de concederem benefícios, incentivos fiscais ou isenções tributárias aos entes federados que possuem a competência para instituir e arrecadar esse imposto.

Ressalta-se que para o nascimento desses benefícios, todos os entes federativos competentes para instituir e arrecadar o ICMS devem ratificar o convênio:

Avançando no tema, salientamos ser imprescindível que todos os Estados e o Distrito Federal ratifiquem o convênio interestadual para que a isenção do ICMS nasça. De fato, a Constituição exige que eles se coloquem de acordo, para que tal benefício passe a ter existência jurídica. (CARRAZZA, 2002, p. 367)

Ainda segundo o doutrinador, essa obrigatoriedade entre os entes se dá com o intuito de evitar a Guerra Fiscal entre as regiões de nosso País. (2002, p.367).

Ives Gandra (2013, p. 22-29) também leciona sobre o tema: 
[...] o texto constitucional, quando se refere à deliberação dos Estados e Distrito Federal, no tocante aos estímulos fiscais outorgados, necessariamente impõe a deliberação de todos os Estados e Distrito federal, visto que não estabeleceu quorum mínimo.

Por esta linha de raciocínio, entendo que a unanimidade exigida pelo Confaz não decorre da legislação infraconstitucional, mas decorre, à luz da Constituição de 1988, do próprio texto supremo, tese, aliás, fortalecida com minha interpretação do art. 146-A da Lei Suprema.

Portanto, verifica-se que CONFAZ tem enorme função quanto aos benefícios fiscais e às isenções tributárias concedidas aos contribuintes na tributação do ICMS em nosso País, haja vista que é por meio de seus membros que os convênios são firmados e posteriormente, quando aprovados pelas respectivas Casas Legislativas de cada Estado-membro e Distrito Federal, tornam-se leis, passando a compor o direito interno desses entes federativos.

A técnica dos convênios reflete o dever-ser do processo legislativo de que se utiliza o Estado-membro para exercer sua competência exonerativa em relação ao ICMS. Os convênios de Estados expressam uma solução de compromisso entre a necessidade de preservar a autonomia tributária dos entes locais, sem risco para a unidade econômica da Federação e a realidade de um imposto nacional. (COELHO, 1996, p. 293)

Como se verifica, os convênios firmados pelos Estados-membros e Distrito Federal junto ao CONFAZ trazem consigo uma tentativa clara de isonomia aos Estados Federativos, haja vista que todos estes devem participar de suas elaborações e posteriormente dar a eles um status de lei, diminuindo a possibilidade de incidência da Guerra Fiscal no Brasil.

Todavia, em que pese os aludidos convênios, os Estados-membros, com o intuito de atraírem capitais e investimentos privados para seu território, concedem a determinadas empresas incentivos tributários, que reduzem o valor da tributação do ICMS nas operações interestaduais. Esses são concedidos 
em razão de que os investimentos empresariais, em regra, não se destinariam ao território do Estado cedente sem tal vantagem. Por esse motivo, o STF, em tentativa de acabar ou diminuir a Guerra Fiscal vem declarando insistentemente a inconstitucionalidade desses incentivos, in verbis:

[...] 10. A outorga de benefícios fiscais relativos ao ICMS, sem a prévia e necessária celebração de convênio entre os Estados e o Distrito Federal é manifestamente inconstitucional. Precedentes: ADI 2906/RJ, rel. Min. Marco Aurélio, 1․6.2011; ADI 2376/RJ, rel. Min. Marco Aurélio, 1․6.2011; ADI 3674/ RJ, rel. Min. Marco Aurélio, 1․6.2011; ADI 3413/RJ, rel. Min. Marco Aurélio, 1․6.2011; ADI 4457/PR, rel. Min. Marco Aurélio, 1․6.2011; ADI 3794/PR, rel. Min. Joaquim Barbosa, $1^{\circ}$.6.2011; ADI 2688/PR, rel. Min. Joaquim Barbosa, $1^{\circ} .6 .2011$; ADI 1247/PA, rel. Min. Dias Toffolli, 1․6.2011; ADI 3702/ ES, rel. Min. Dias Toffoli, $1^{\circ} .6 .2011$; ADI 4152/SP, rel. Min. Cezar Peluso, 1․6.2011; ADI 3664/RJ, rel. Min. Cezar Peluso, 1․6.2011; ADI 3803/PR, rel. Min. Cezar Peluso, $1^{\circ} .6 .2011$; ADI 2549/DF, rel. Min. Ricardo Lewandowski, $1^{\circ} .6 .2011 .^{3}$

Contudo, posteriormente a declaração de inconstitucionalidade, os entes federados editam novas leis concedendo novamente os benefícios. Em razão dessa desobediência dos Estados-membros e Distrito Federal, essa medida para encerrar a Guerra Fiscal não vem sendo satisfatória:

No tocante à propositura de ADINs pelos Estados prejudicados junto ao STF, não raras vezes, quando aquele Tribunal Constitucional Maior lhes concede liminares favoráveis, suspendendo a eficácia da medida política (o STF, instado a manifestar-se sobre a matéria, construiu reiterado entendimento sobre a inconstitucionalidade da concessão, pelo Estado, de benefícios fiscais sem Convênio prévio celebrado nas hostes do CONFAZ), os Estados mudam formalmente o instrumento legislativo, continuando a conceder os mesmos favores fiscais sob outra roupagem. (CARVALHO, 2006, p. 31)

${ }^{3}$ ADI 429/CE, Rel. Min. Luiz Fux, julgada em 04/08/2010. 
Destarte, mesmo inconstitucionais e flagrantemente irregulares no que tange à competência dos entes federativos para desonerar (conceder benefícios), os Estados-membros e Distrito Federal, permanecem a guerrear pelos investimentos privados, concedendo incansáveis benefícios às empresas.

Em virtude deste cenário, para tentar encerrar conflito afeito à guerra fiscal, em agosto de 2017 foi publicada a Lei Complementar 160/2017 cujo texto, em síntese, permitiu aos Estados e Distrito Federal firmarem convênio para manter os incentivos por mais tempo e perdoar dívidas tributárias de contribuintes autuados.

Este convênio foi, enfim, publicado em 18/12/2017 (Convênio 190/2017) estabelecendo as regras para convalidação dos benefícios fiscais existentes.

Mencionado Convênio condicionou a validação dos benefícios fiscais à publicação no Diário Oficial do Estado ou do Distrito Federal da relação com a identificação de todos os atos normativos. Melhor explicando: para que a empresa obtenha o perdão administrativo, cada Estado deve publicar uma lista dos benefícios fiscais que concedeu e, três meses depois, apresentar perante o CONFAZ a "documentação comprobatória correspondente aos atos concessivos dos benefícios fiscais". Os benefícios fiscais não publicados deverão ser revogados. Tudo isso será público, disponibilizado pelo Confaz no Portal Nacional da Transparência Tributária.

Ou seja, o legislador oportunizou a todos os Estados sanarem os supostos equívocos praticados com a concessão pretérita de benefícios fiscais não convalidados pelo CONFAZ.

Todavia, para isso ocorra, há necessidade de expressa anuência de $2 / 3$ das unidades federadas, e de $1 / 3$ de cada uma das unidades federadas de cada uma das 5 regiões do país.

Disto resulta que, a despeito das novas disposições normativas, a glosa de créditos aos contribuintes irá persistir. Isto, pois, se não houver o quórum acima para autorização dos incentivos se irá a glosa dos créditos contra quem não deu causa ao indigitado conflito (já que os Estados concessores são responsáveis), o que, conforme vertente deste trabalho, se configura grave afronta ao fundamento da Ordem Econômica Constitucional, notadamente ao que revela a livre iniciativa, como núcleo estruturante dos 
negócios que se dão no ambiente brasileiro.

\section{A GLOSA DOS CRÉDITOS FISCAIS E A AFRONTA AO FUNDAMENTO DA ORDEM ECONÔMICA PRECONIZADOR DA LIVRE INICIATIVA PREVISTA NA CARTA CONSTITUCIONAL DE 1988.}

\subsection{A glosa de créditos fiscais}

Uma saída encontrada pelo Estado para afastar os efeitos decorrentes da guerra fiscal foi editar atos normativos com vistas a punir seus próprios contribuintes, por meio da chamada glosa de crédito.

Nesse passo, salienta-se que a glosa de crédito ocorre de duas maneiras: a primeira quando o Estado, por meio de edição de normas, retira do contribuinte o direito aos créditos oriundos das prestações anteriores; ou seja, quando este for recolher o ICMS, deverá arcar com a parte que o outro sujeito passivo creditou em sua nota fiscal mas que no entanto deixou de recolher em virtude de possuir benefícios e incentivos fiscais (crédito presumido).

Exemplificando, o contribuinte do Estado $\mathrm{X}$ declara em sua nota fiscal o recolhimento da quantia de $\mathrm{R} \$ 200,00$ (duzentos reais) à título de ICMS, de modo que o contribuinte posterior, situado no Estado $Y$, ao efetuar nova circulação da mercadoria, deveria arcar com R \$300,00 (trezentos reais) de ICMS; todavia, por força do princípio da não-cumulativade, se credita do valor anteriormente recolhido, sendo necessário o pagamento de apenas $\mathrm{R} \$ 100,00$ (cem reais) para quitar integralmente o imposto devido em decorrência dessa operação.

Ocorre que, por possuir benefícios fiscais, o contribuinte do Estado $\mathrm{X}$ recolheu apenas $R \$ 100,00$ (cem reais); isto é, menos do que descreveu em nota fiscal, motivo pelo qual o Estado $Y$ retira de seu contribuinte a possibilidade de creditar-se do valor integral contido na aludida nota, devendo este realizar o pagamento de $\mathrm{R} \$ 200,00$ (duzentos reais), onde $\mathrm{R} \$ 100,00$ (cem reais) refere-se a sua parte do ICMS e R $\$ 100,00$ (cem reais) diz respeito ao acréscimo da quantia não recolhida pelo sujeito passivo anterior.

A segunda forma de ocorrência da glosa de crédito se dá por meio de fiscalização, a qual acontece após o contribuinte ter se creditado do valor de- 
clarado a título de ICMS em nota fiscal pelo sujeito passivo situado no Estado concessor de benefícios sem anuência do CONFAZ.

Essa forma resulta em autos de infrações aos contribuintes que se valeram do crédito destacado em documentos fiscais das prestações anteriores, sem que, contudo, fossem devidamente recolhidos em razão de os contribuintes destas gozarem de benefícios tidos como irregulares.

Verifica-se, portanto, que independente da forma em que acontece, a glosa de crédito é o ato administrativo pelo qual os Estados anulam o direito de seus contribuintes aos créditos oriundos de prestações anteriores.

\subsection{A glosa de crédito como afronta ao fundamento da livre iniciativa prevista na Carta Constitucional de 1988}

A glosa de crédito traz um exorbitante prejuízo aos contribuintes visto que estes são punidos por observarem o princípio da não-cumulativadade - regra matriz do ICMS - creditando-se de um imposto declarado em documento fiscal de operações anteriores, o qual o contribuinte entende como legítimo, haja vista não possuir conhecimento acerca dos benefícios e incentivos fiscais concedidos irregularmente por outras unidades federativas aos seus contribuintes.

Há de ressaltar que tal punição onera consideravelmente o contribuinte, sendo este o maior prejudicado de uma batalha que nem se quer faz parte (Guerra Fiscal), onde não raras às vezes se vê obrigado a encerrar as atividades de sua empresa em razão de não conseguir arcar com as vertiginosas multas perpetrado pelos Estados.

Na verdade, a empresa brasileira está sendo punida por algo que não deu causa. A atitude dos Estados de lavrar auto de infração em face de contribuintes não é outra senão a de transferir aos destinatários de mercadorias/ serviços (os contribuintes), o ônus de analisar a legalidade/constitucionalidade de incentivo fiscal concedido pelo Estado de origem aos seus fornecedores. Certo é que o contribuinte não pode ser penalizado por ato de terceiro (Estado concessor de crédito) e tampouco deve ser impelido ao juízo de constitucionalidade de incentivos fiscais. 
Os contribuintes, na verdade, são apenas vítimas de uma guerra que não lhes pertence. Acaso essa situação se perpetue, estar-se-á dando azo à visceral lesão ao fundamento da ordem econômica disposta no artigo 170 da Constituição Federal de 1988, que trouxe para o Brasil os delineamentos de uma Constituição Econômica.

Sobre a Constituição Econômica, Vital Moreira (1979, p. 15), em dissertação intitulada Economia e Constituição, afirma que a expressão “constituição econômica" parece ter aparecido pela primeira vez pela pena do fisiocrata Baudeau, que com ela encabeçou um dos capítulos da sua Première Introduction à La Philosophie Économique (1771). Significava aí o conjunto dos preceitos jurídicos reguladores da "societé économique".

Porém, foi na literatura econômica que a expressão em primeiro lugar obteve um delineamento, mas com sentido diverso, significando o mesmo que estrutura econômica ou sistema econômico, ou seja, os elementos estruturais que determinam as leis e condicionam o processo de evolução da economia.

Moreira (1979, p. 22) entende que foi após a Primeira Guerra Mundial - marco do fim de uma época econômica e política do capitalismo e início de outra - que o conceito de Constituição Econômica surge de forma mais incisiva.

As Constituições elaboradas após o final da Primeira Guerra Mundial tem algumas características comuns: a declaração, ao lado dos tradicionais direitos individuais, dos chamados direitos sociais ou direitos de prestação, ligados ao princípio da igualdade material que dependem de prestações diretas ou indiretas do Estado para serem usufruídos pelos cidadãos: estas novas Constituições são consideradas parte do novo "constitucionalismo social" que se estabelece em boa parte dos Estados europeus e em alguns americanos. Em torno destas Constituições, adjetivadas de sociais, programáticas ou econômicas, vai se dar um intenso debate teórico e ideológico.

Bercovici (2005, p. 13) entende que a Constituição Econômica não é uma inovação do constitucionalismo social do século $X X$, mas está presente em todas as Constituições, inclusive nas liberais dos séculos XVIII e XIX. Todas as Constituições liberais possuíam disposições econômicas em seus textos, as quais buscavam sancionar o existente, garantindo os fundamentos do sistema econômico liberal, ao prever dispositivos que preservavam a liberdade de co- 
mércio, de indústria, a liberdade contratual e, fundamentalmente, os direitos de propriedade.

O debate em torno das Constituições Econômicas intensificou-se no século XX, com a Constituição Mexicana de 1917 e a Constituição de Weimar de 1919. Formalmente, as Constituições do século XX diferenciam-se das anteriores por, entre outros motivos, conterem uma expressão formal de Constituição Econômica, com uma estrutura mais ou menos sistematizada em um capítulo próprio.

A diferença essencial que surge a partir do constitucionalismo social do século XX e que delimita o debate sobre a Constituição Econômica é o fato de que estas Constituições não pretendem mais receber a estrutura econômica existente, mas alterá-la: assim, positivam tarefas e políticas a serem realizadas no domínio econômico e social para atingir certos objetivos. A ordem econômica destas Constituições é programática, dirigente. A Constituição econômica que se concebe surge quando a estrutura econômica se revela problemática, quando se esvai a crença na harmonia operada pelo mercado. Então surge com a pretensão de ser uma nova ordem econômica, de molde a alterar a ordem econômica existente, rejeitando o mito da auto-regulação do mercado.

Na verdade, o que caracteriza a Constituição Econômica é a sua inserção, nas constituições modernas, do econômico como material constitucionalizável e a atribuição a ele de um "quadro de ordem", isto é, a sua estruturação jurídica mais ou menos sistemática, abrangendo todos os domínios do econômico. Consoante já mencionado, esse quadro de ordem não pretende receber a estrutura econômica existente - ao invés, pretende alterá-la. O que caracteriza essa ordem constitucional da economia é o fato de integrar declarações de tarefas a realizar na economia, no sentido de conduzir a certos objetivos.

Volvendo especificamente para o caso brasileiro, há de ser dito que, embora tenha sido elaborada num momento de reflorescimento das idéias pertinentes à limitação da atuação do Estado e de redução dos direitos de caráter social, a Constituição Brasileira de 1988 adotou o figurino do Estado de bem -estar social, o que é compreensível numa sociedade que, à época, apresentava profundos padrões de desigualdades.

Bradando sobre a realidade em menção, GRAU assim escreveu: 
Erradicação da pobreza e da marginalização, bem assim redução das desigualdades sociais e regionais, são objetivos afins e complementares daquele atinente à promoção do desenvolvimento econômico.

[...] Existe o reconhecimento explícito de marcas que caracterizam a realidade nacional: pobreza, marginalização e desigualdades, sociais e regionais. Eis um quadro de subdesenvolvimento, incontestado que, todavia, pretende reverter. Essa reversão nada tem, porém, em relação aos padrões do capitalismo, de subversiva. É revolucionária apenas quando voltada apenas enquanto voltada à modernização do próprio capitalismo. Dir-se-á que a Constituição, aí, nada mais postula, no seu caráter de Constituição dirigente, senão rompimento do processo de subdesenvolvimento no qual estamos imersos [...] (GRAU, 2003, p. 218)

Foi neste cenário que a Constituição Federal de 1988, traçou, em seu art. 170, os ditames da ordem econômica.

No capítulo voltado à mencionada ordem econômica, observa-se a reunião de princípios, normas e institutos jurídicos voltados para sua regulamentação.

Esse conjunto de preceitos voltados à regulação da economia em nível Constitucional, recebeu o nome de "Constitucionalização da Ordem Econômica". (ARAÚJO, 1999, p.347).

Convém destacar neste trabalho que a disposição nuclear desta ordem econômica brasileira está retratada na primeira parte do art. 170 da Constituição, ao prescrever: "A ordem econômica, fundada na valorização do trabalho humano e na livre iniciativa, tem por fim assegurar a todos existência digna, conforme os ditames da justiça social..."

Extrai-se deste cenário que a livre iniciativa é fundamento da ordem econômica. Ao tratar sobre os fundamentos da Ordem Econômica, SILVA (2002, p. 765), esclarece que:

Em primeiro lugar quer dizer precisamente que a Constituição consagra uma economia de mercado, de natureza capitalista, pois a iniciativa privada é um princípio básico da ordem 
capitalista. Em segundo lugar significa que, embora capitalista, a ordem econômica dá prioridades ao trabalho humano sobre todos os demais valores da economia de mercado.

Por ser uma declaração de princípio, o professor Silva afirma que essa prioridade tem o sentido de orientar a intervenção do Estado na Economia, a fim de fazer valer os valores sociais do trabalho que, ao lado da iniciativa privada, constituem o fundamento não só da ordem econômica, mas da própria República Federativa do Brasil.

Ao tratar da valorização do trabalho o jurista Eros Grau (p.64, 2004) assevera que esta caracterização representa uma preocupação com um tratamento distinto ao trabalho que, "em uma sociedade capitalista moderna, peculiariza-se na medida em o trabalho passa a receber proteção não meramente filantrópica, porém politicamente racional". Quando a capacidade laboral é interrompida ou cessa, os aspectos securitários amoldam-se no Direito Previdenciário. Mas sendo o trabalho um fator de produção, por certo o tema diz respeito à política econômica, melhor conduzida quando inserida na normatividade propiciada pelo Direito Econômico, sempre a partir da Constituição Federal (PETTER, 2005, p. 167)

Quanto à livre iniciativa, que é o que mais interessa ao corte metodológico deste trabalho, esta ser traduzida no direito que todos têm de se lançarem ao mercado de produção de bens e serviços por sua conta e risco (PETTER, 2005, p. 177).

Para REALE:

Não é senão a projeção da liberdade individual no plano da produção, circulação e distribuição das riquezas, assegurando não apenas a livre escolha das profissões e das atividades econômicas, mas também a autônoma eleição dos processos ou meios julgados mais adequados à consecução dos fins visados.(REALE, 1988, p.a-3)

Conforme os autores Luiz Alberto David Araújo e Vidal Serrano Nunes Júnior, a livre iniciativa estampada no texto constitucional possui uma densidade normativa, da qual se pode extrair a "faculdade de criar e explorar uma 
atividade econômica a título privado" e a "não sujeição a qualquer restrição estatal, senão em virtude de lei" (ARAUJO; SERRANO JUNIOR, 2006, p. 466).

Silva (2002, p.765) comenta que a livre iniciativa consagra uma economia de mercado, de natureza capitalista, já que é um princípio básico da ordem capitalista. Ensina que "a liberdade de iniciativa envolve a liberdade de indústria e comércio ou liberdade de empresa e a liberdade de contrato".

Eros Grau, por sua vez, pondera que a liberdade de iniciativa não se identifica apenas com a liberdade de empresa, pois abrange todas as formas de produção individuais ou coletivas, dando ensejo às iniciativas privada, cooperativa, autogestionária e pública (2004, p. 186-187).

Certo é que a livre iniciativa sugere a liberdade de empresa, que pode ser entendida sobre três vertentes: "liberdade de investimento ou acesso; liberdade de organização; liberdade de contratação" (VAZ apud ARAUJO; SERRANO JUNIOR, 2006, p. 465).

Cotejando tais ensinamentos ao objetivo deste trabalho, deve-se afirmar que a glosa ao crédito decorrente de guerra fiscal com punição da empresa que utiliza de tais créditos é medida que afronta os postulados da Ordem Econômica Constituição porquanto as multas que são impostas pelos Estados revestem-se em verdadeiros atos que obstam a livre iniciativa. Isto, pois, as empresas, ao invés de empreender sua atividade e obter os benefícios da lei (porque os créditos são usufruídos com base na lei), quedam-se coagidas e optam por desenvolver as atividades de forma tímida, sem aproveitamento dos créditos a que fazem jus, circunstância que certamente afetará a geração de empregos, perpetuando, assim, a lesão ao também postulado da Ordem Econômica pertinente à valorização do trabalho humano.

\section{CONSIDERAÇÕES FINAIS}

As linhas traçadas neste trabalho evidenciaram que o ICMS - Imposto sobre Circulação de Bens e Mercadorias - é a maior receita dos Estados-membros e Distrito Federal, motivo pelo qual, quando um Estado concede benefícios e incentivos ao ICMS, outros entes federados também o fazem na incessante busca de recursos para seu território. 
Tais benefícios revestem-se nas formas de isenção, redução da base de cálculo, redução de alíquotas, crédito presumido, dentre outros, conferidos pelos Estados que acabam por reduzir os tributos para atrair empresas que optem por se instalar no Estado redutor e investir na geração de emprego e produção de riquezas de seu território.

Todavia, conforme demonstrou-se ao longo deste trabalho, os incentivos fiscais somente podem ser concedidos com expressa anuência do CONFAZ (Conselho Nacional de Política Fazendária), a quem compete promover a celebração de convênios para efeito de concessão ou revogação de isenções, incentivos e benefícios fiscais do imposto.

Diante de ausência de consenso e muitos Estados acabam concedendo benefícios sem autorização do CONFAZ, derivando daí a guerra fiscal.

Por esse motivo, o Supremo Tribunal Federal, visando por termo à Guerra Fiscal, vem declarando insistentemente a inconstitucionalidade desses incentivos. Posteriormente à declaração de inconstitucionalidade, os entes federados editam novas leis concedendo novamente os benefícios.

Buscando alternativas para diminuir seus prejuízos, os Estados prejudicados promovem a glosa de crédito, a qual acontece com lançamento de multas vertiginosas, após o contribuinte ter se creditado do valor declarado a título de ICMS em nota fiscal pelo sujeito passivo situado no Estado concessor de benefícios sem anuência do CONFAZ.

Em virtude deste cenário, para tentar encerrar conflito afeito à guerra fiscal, em agosto de 2017 foi publicada a Lei Complementar 160/2017 cujo texto, em síntese, permitiu aos Estados e Distrito Federal firmarem convênio para manter os incentivos por mais tempo e perdoar dívidas tributárias de contribuintes autuados.

Mencionado Convênio condicionou a validação dos benefícios fiscais à publicação no Diário Oficial do Estado ou do Distrito Federal da relação com a identificação de todos os atos normativos. Melhor explicando: para que a empresa obtenha o perdão administrativo, cada Estado deve publicar uma lista dos benefícios fiscais que concedeu e, três meses depois, apresentar perante $\mathrm{o}$ CONFAZ a "documentação comprobatória correspondente aos atos concessivos dos benefícios fiscais". Os benefícios fiscais não publicados deverão ser 
revogados. Tudo isso será público, disponibilizado pelo Confaz no Portal Nacional da Transparência Tributária.

Ou seja, o legislador oportunizou a todos os Estados sanarem os supostos equívocos praticados com a concessão pretérita de benefícios fiscais não convalidados pelo CONFAZ.

Todavia, para que isso ocorra, há necessidade de expressa anuência de $2 / 3$ das unidades federadas, e de $1 / 3$ de cada uma das unidades federadas de cada uma das 5 regiões do país.

Disto resulta que, a despeito das novas disposições normativas, a glosa de créditos aos contribuintes irá persistir, pois, se não houver o quórum para autorização dos créditos, as Fazendas dos Estados continuarão multando os contribuintes,

Este cenário revela que a situação dá azo à visceral lesão ao fundamento da ordem econômica disposta no artigo 170 da Constituição Federal de 1988, que trouxe para o Brasil os delineamentos de uma Constituição Econômica.

Ao fim e ao cabo, pode-se afirmar que a glosa ao crédito decorrente de guerra fiscal com punição da empresa e dos contribuintes que utilizam de tais créditos é medida que afronta os postulados da Ordem Econômica Constituição, porquanto as multas que são impostas pelos Estados revestem-se em verdadeiros atos que obstam a livre iniciativa. Isto, pois, as empresas, ao invés de empreender sua atividade e obter os benefícios da lei (porque os créditos são usufruídos com base na lei), quedam-se coagidas e optam por desenvolver as atividades de forma tímida, sem aproveitamento dos créditos a que fazem jus, circunstância que certamente afetará a geração de empregos, perpetuando, assim, a lesão ao também postulado da Ordem Econômica pertinente à valorização do trabalho humano. 


\section{REFERÊNCIAS}

ARZUA, Heron. ICMS: caráter nacional: guerra fiscal e seus mecanismos de atuação: o regime dos incentivos fiscais no ICMS. Revista de Direito Tributário, São Paulo, Malheiros, n. 81.

BALEEIRO, Aliomar. Direito Tributário Brasileiro. $11^{\text {a }}$ ed. Rio de Janeiro: Editora Forense, 2010.

BERCOVICI, Gilberto. Constituição econômica e desenvolvimento. São Paulo: Malheiros Editores, 2005

BRASIL, Constituição 1988. Constituição da República Federativa do Brasil. Disponível em: http://www.planalto

. Lei n ${ }^{\circ}$ 5.172, de 25 de outubro de 1966. Código Tributário Nacional. Diário Oficial da União, Brasília, DF, 25 out. 1966.

Lei Complementar $\mathbf{n}^{0}$ 24, de 07 de janeiro de 1975. Convênios para a Concessão de Isenções ao ICMS. Diário Oficial da União, Brasília, DF, 07 jan. 1975.

Sobre o CONFAZ: Conselho Nacional de Política Fazendária. Disponível em: http://www.sefaz.mt.gov.br/portal/confaz/?acao=sobre. Acesso em: 19 out. 2016.

Competência. Disponível em: https://www.confaz.fazenda.gov.br/menude-apoio/competencias. Acesso em: 25 set. 2016.

. CONFAZ. Disponível em: http://www.sefaz.pi.gov.br/index.php/institucional/teste. Acesso em: 17 out. 2016.

CANOTILHO, J. J. Gomes. Direito Constitucional e teoria da Constituição. Coimbra: Almedina, 1999.

CAMARGO, R. A.L. Breve Introdução ao Direito Econômico. Porto Alegre: Sergio Antonio Fabris, 1993.

CARRAZA, Roque Antônio. Curso de Direito Constitucional Tributário. $18^{\mathrm{a}}$ ed. São Paulo: Malheiros Editores, 2002.

CARRAZA, Roque Antônio. ICMS. $8^{\mathrm{a}}$ ed. São Paulo: Malheiros Editores, 2002. 
COÊLHO, Sacha Calmon Navarro. Curso de direito tributário brasileiro. Rio de Janeiro: Forense, 1996.

GRAU, Eros Roberto. A ordem econômica na Constituição de 1988. 8.ed. São Paulo: Malheiros, 2003.

MACHADO, Hugo de Brito. Curso de Direito Tributário. $31^{\text {a }}$ ed. São Paulo: Malheiros Editores, 2010.

MARQUES, Klaus Eduardo Rodrigues. A guerra fiscal do ICMS: uma análise crítica sobre as glosas de crédito. São Paulo: MP Editora, 2010.

MARTINS, Ives Gandra. Estímulos Fiscais do ICMS e a Unanimidade do CONFAZ. In. Revista CEJ, Brasília, Ano XVII, n. 59, jan-abr, 2013.

MELO, José Eduardo Soares de. ICMS: teoria e prática. São Paulo: Dialética, 2004.

MOREIRA, Vital. Economia e Constituição. Coimbra: Editora Limitada, 1979. A ordem jurídica do capitalismo. Centelha: Coimbra, 1977. 